\title{
TURBIDITOS E A GLACIACTÃO DO FINAL DO PROTEROZÓICO SUPERIOR NO CINTURÃO PARAGUAI, MATO GROSSO
}

\author{
CARLOS JOSÉ SOUZA DE ALVARENGA*
}

\begin{abstract}
TURBIDITES AND THE UPPER PROTEROZOIC GLACIATION IN THE PARAGUAI FOLDED BELT, MATO GROSSO. The Puga and Bauxi formations do not show an unconformable contact with the Cuiabá Group but there is a gradual change from the glaciomarine environment, partially represented by the Puga Formation, to turbidites of the Cuiabá Group. Turbidity currents might have been generated due to landsliding of the glacial deposits over the Amazonic Craton border. Diamictite and resedimented conglomerates associated with turbidity flows are considered to belong to a glaciomarine facies produced by sub-aqueous gravity flows. The distal facies is made up of fine grained sediments deposited from suspension. Limestones of the Araras Formation are thought to be deposited after the glaciation. This formation, near Corumbá, bears Ediacaran type of faune, suggesting an age Vendian for the sedimentation. The sedimentary and metassedimentary units that belong to the Paraguai fold belt are affected by the Brasiliano Cycle, which developed in the region during the Upper Proterozoic and the Fanerozoic boundary. A few post-tectonic granitic plutons of about $500 \mathrm{Ma}$ age are observed in the middle part of the belt.
\end{abstract}

INTRODUÇÃO Na margem sudeste do Cráton Amazônico em Mato Grosso, situa-se o Cinturão Paraguai, uma faixa de dobramentos polifásicos afetada pelo ciclo tectônico Brasiliano. A extensão deste cinturão para a região de Mato Grosso do Sul sofre uma interrupçâo dos afloramentos devido à cobertura dos sedimentos quaternários da bacia do Pantanal, vindo a reaparecer na região da Serra da Bodoquena às margens do Complexo Rio Apa (Fig. 1).

O Cinturão Paraguai pode ser individualizado em estruturas brasilianas não-metamórficas e metamórficas (Almeida 1984, 1985). As rochas metamórficas do Grupo Cuiabá, localizadas na zona tectônica interna apresentam um registro de quatro fases de deformação e um metamorfismo do fácies xisto verde baixo, que apenas localmente chega a atingir a zona de biotita (Alvarenga 1986). As seqüências sedimentares não-metamórficas, localizadas na zona tectônica externa e na parte pericratônica, incluem os sedimentos das formaçōes Bauxi, Puga, Araras, Raizama e Diamantino, que foram aparentemente dobrados apenas por uma fase, mostrando um decréscimo na intensidade dessas deformaçōes em direção ao Cráton Amazônico a noroeste.

Este trabalho, sustentado em várias observaçōes de campo, apresenta os aspectos sedimentológicos presentes nas zorias externa e interna do Cinturão Paraguai, mostrando a existência de uma passagem gradual de um ambiente glaciomarinho a glaciomarinho com correntes de turbidez para um ambiente turbidítico em sua zona mais interna.

ESTRATIGRAFIA A estratigrafia da faixa Paraguai tem sido apresentada em colunas que, quando comparadas, são conflitantes no que se refere às relaçöes de contato entre suas unidades basais, representadas pelo Grupo Cuiabá e as formaçōes Bauxi e Puga. Alvarenga (1984) analisou e discutiu sobre as diferentes colunas propostas para a regiāo e concluiu, naquela ocasiâo, serem insuficientes os dados existentes para se fazer uma interpretação correta sobre as relaçōes de contato entre as unidades basais. Almeida (1984), apesar de optar pelas interpretações de Figueiredo \& Olivati (1974) e de Ribeiro Filho et al. (1975), que colocam uma discordância angular entre o Grupo Cuiabá e a Formação Bauxi, reconhece que o topo do Grupo Cuiabá é de posição estratigráfica incerta com as formações superiores e aventa a possibilidade de correlatividade entre parte do Grupo Cuiabá e a Formação Bauxi.

Neste trabalho, tendo em vista a existência de importantes variaçōes de fácies laterais entre as unidades basais do cinturão, optou-se por uma subdivisão informal de maneira a dar ênfase e melhor caracterizar seus aspectos sedimentológicos comuns (Figs. 2 e 3 ).

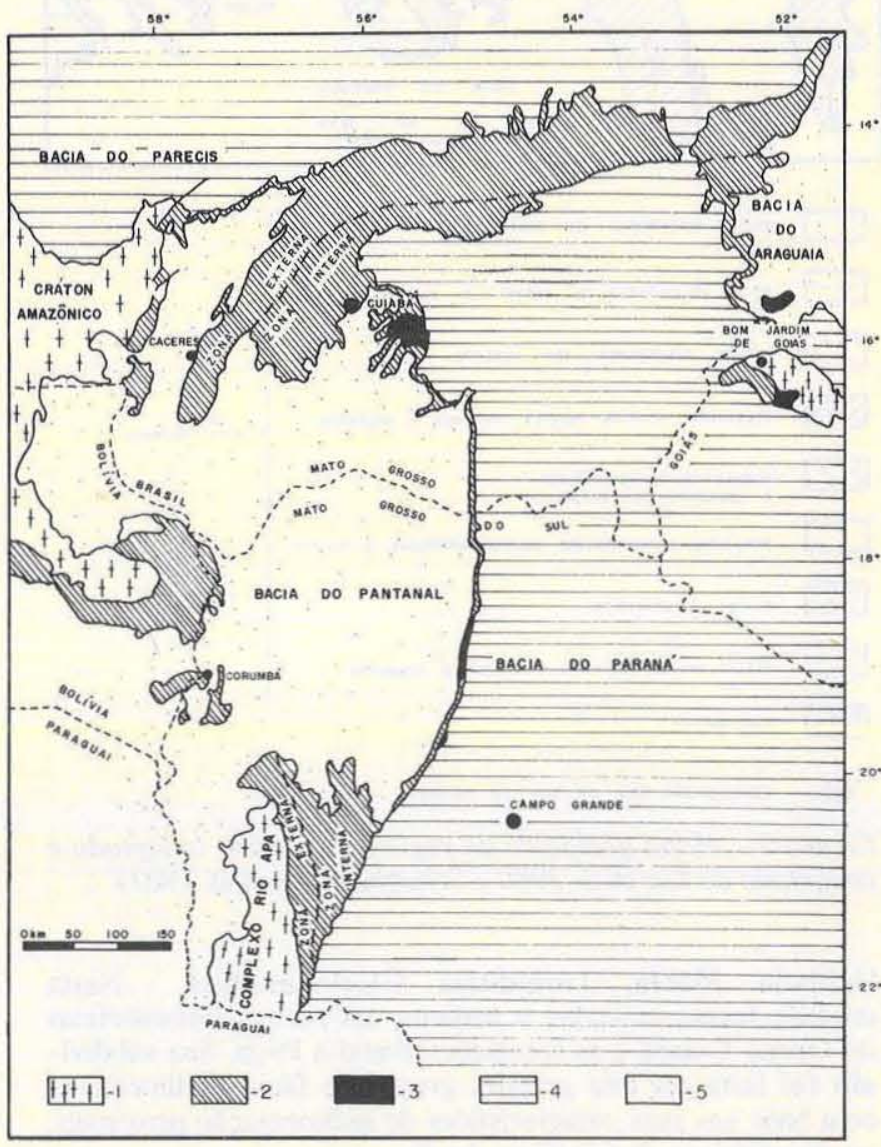

Figura 1 - Situação do Cinturão Paraguai e a geologia adjacente; 1 . embasamento de idade arqueana, proterozóica inferior e média; 2. unidades do Proterozóico Superior, incluindo a sedimentação cratônica sub-horizontal e a faixa de dobramentos a leste e sudeste; 3. granitos intrusivos eocambrianos; 4. bacias paleozóicas-mesozóicas do Paraná e do Parecis; $\mathbf{5}$. sedimentos quaternários das bacias do Pantanal e Araguaia. (Mapa adaptado e compilado de Schobbenhaus et al. 1981 e Litherland \& Bloomfield 1981) 
Unidade Inferior Desenvolvida em uma restrita área do Grupo Cuiabá, no núcleo da anticlinal de Bento Gomes (Fig. 2 ), esta unidade se caracteriza pela grande quantidade de filitos grafitosos associados a filitos, quartzitos e dolomitos. Esta unidade foi, estratigraficamente, individualizada por Luz et al. (1980) nas subunidades 1 e 2 do Grupo Cuiabá.
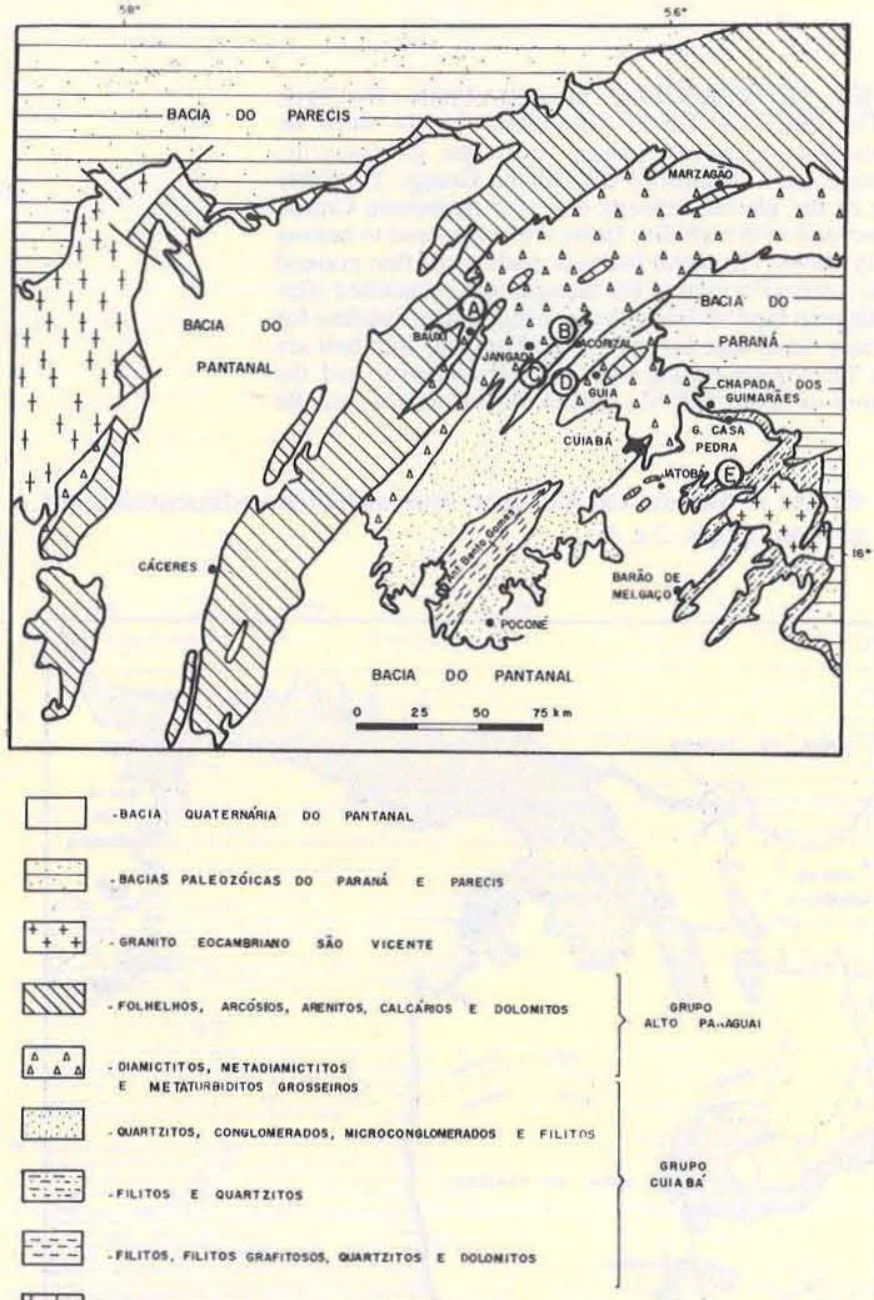

(A)

Localizacão oAs colunas da FIGURA 4

Figura 2 - Mapa geológico da região de Cuiabá (adaptado e compilado de Luz et al. 1980 e Schobbenhaus et al. 1981)

Unidade Média, Turbidítica Glaciogenética Nesta unidade foram incluídas o restante das rochas metamórficas do Grupo Cuiabá e as formações Bauxi e Puga. Sua subdivisẫo foi feita em três grandes grupos de fácies sedimentares com base em suas características de sedimentação proximais, intermediárias e distais (Figs. 4 e 5).

FÁCIES PROXIMAIS Localizadas nas partes mais a norte e noroeste do cinturão e estratigraficamente abaixo dos calcários da Formaçāo Araras, esta fácies se caracteriza por apresentar grande quantidade de diamictitos, com variação no percentual de seus clastos, e com camadas de siltitos, quartzitos e conglomerados intercaladas. As melhores exposiçōes desta fácies localizam-se das proximidades do povoado de Bauxi às proximidades de Marzagão. Esta área é parcialmente coincidente com a regiảo considerada por Almeida (1974) como pertencente ao Grupo Jangada e com as áreas mapeadas como subunidades 4, 5 e 7 do Grupo Cuiabá descritas por Luz et al. (1980).

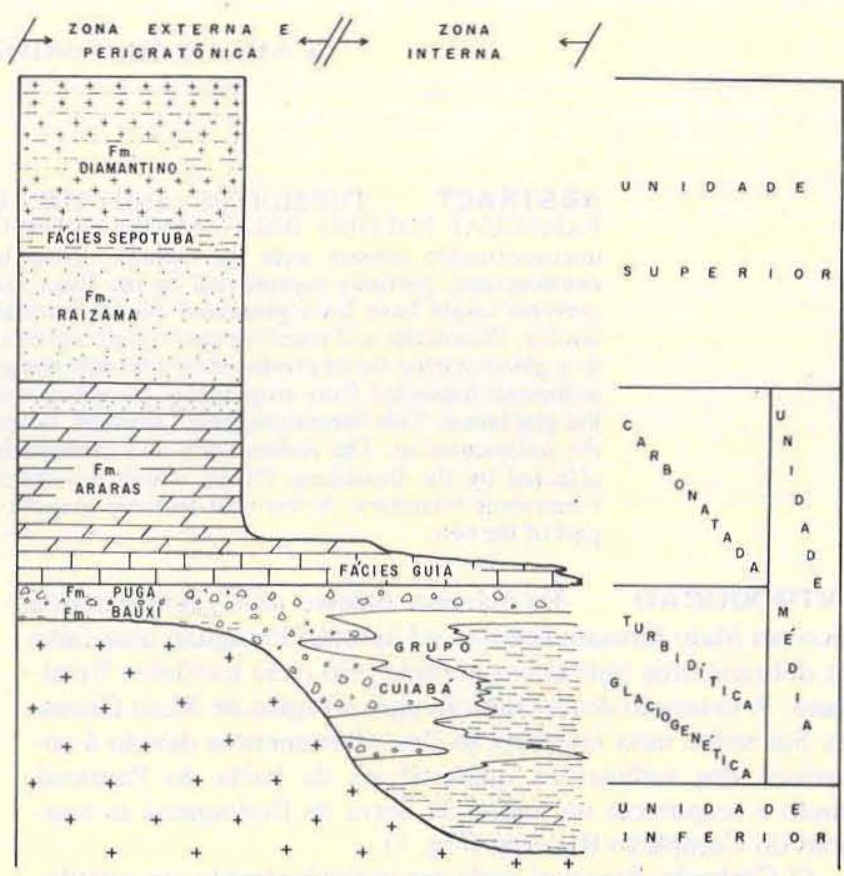

Figura 3 - Coluna estratigráfica esquemática do Cinturão Paraguai em Mato Grosso

Esta fácies proximal apresenta algumas subfácies de acordo $\mathbf{c o m}$ as ilustraçōes da figura 4 . A coluna $\mathbf{A}$ desta figura mostra os sedimentos não-metamórficos da Formação Puga com intercalaçōes de argilitos e diamictitos maciços e laminados; arenitos intercalados com diamictitos também ocorrem na região. A coluna B (Fig. 4) está localizada na regiäo metamórfica próximo a Acorizal e apresenta diamictitos intercalados com conglomerados e arenitos. A coluna $\mathbf{C}$, também composta de metassedimentos, mostra uma grande quantidade de ciclos conglomeráticos, intercalados com quartzitos, que às vezes apresentam os intervalos da seqüência de Bouma (Foto 1). A maioria dos afloramentos desta fácies foram observados em Jangada, Bauxi e Acorizal.

FÁCIES INTERMEDIÁRIAS Esta fácies é composta de filitos com espessas intercalações constituídas de quartzitos, microconglomerados e conglomerados organizados em ciclos de granodecrescência para o topo (Fig. 4-D). Essas espessas intercalações foram interpretadas por Alvarenga (1985) como uma fácies turbidítica grossa do Grupo Cuiabá. Os afloramentos dessas fácies estão incluídos na área mapeada por Luz et al. (1980) como subunidades 3 e parte da 5 do Grupo Cuiabá.

FÁCIES DISTAIS Localizada no extremo sudeste da faixa, esta fácies é composta quase que exclusivamente por filitos, podendo apresentar espessas intercalaçōes compostas de ciclos de quartzitos e metassiltitos às vezes com os intervalos Tb e Tc do ciclo de Bouma, como ocorre na região entre São Vicente e Barão de Melgaço (Fig. 4-E). Os filitos desta fácies são pouco conhecidos por se encontrarem quase que totalmente capeados por formações superficiais ou por se apresentarem bastante alterados. Suas melhores exposições se localizam nos garimpos do Jatobá e da Casa de Pedra. 


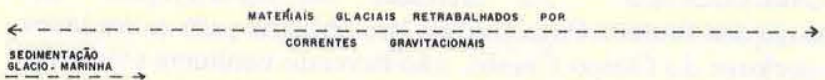

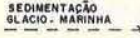

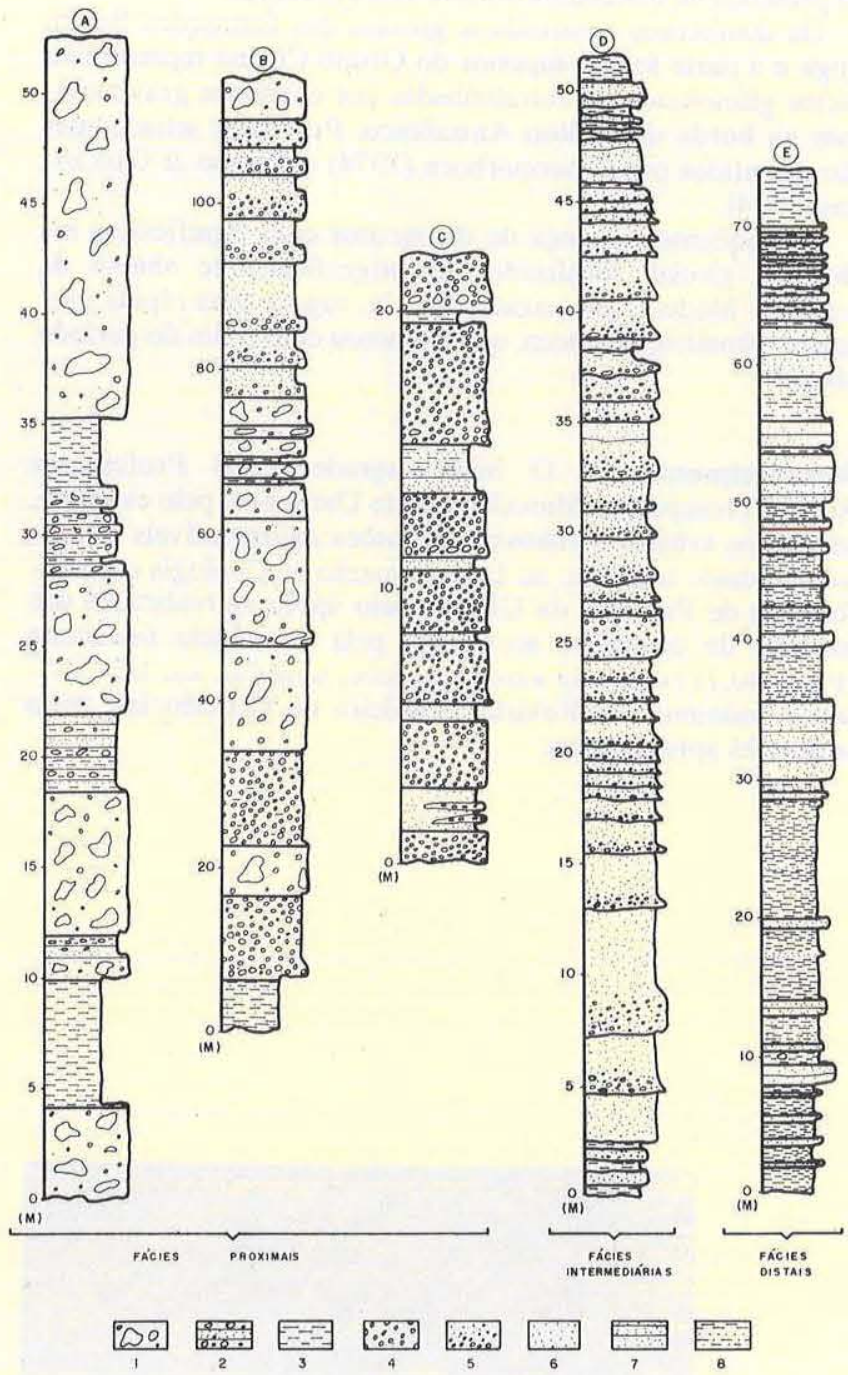

Figura 4 - Distribuição da sedimentação na bacia: 1. diamictitos maciços; 2 . diamictitos laminados; 3 . argilitos; 4. conglomerados; 5. microconglomerados com granodecrescência para o topo; 6. quartzitos maciços; 7. quartzitos estratificados; 8. siltitos e arenitos finos (as colunas $\mathbf{A}, \mathbf{B}, \mathbf{C}, \mathbf{D} e \mathbf{E}$ estão localizadas na figura 2)

Unidade Média Carbonatada Esta unidade é representada pelos calcários e dolomitos da Formação Araras na Província Serrana e pelos calcários e dolomitos com pelitos laminados subordinados da Fácies Guia, estes na área metamórfica do Grupo Cuiabá (Fig. 3).

A Formação Araras, com aproximadamente $1.300 \mathrm{~m}$ de espessura foi dividida em um membro inferior de $200 \mathrm{~m}$ de calcários seguidos por um membro superior dolomítico (Luz et al. 1978, Luz \& Abreu Filho 1978).

A Fácies Guia foi descrita por Almeida (1964) como uma seqüência basal do Grupo Araras, posteriormente elevada por Hennies (1966) à categoria de Formação Guia. Luz et al. (1980) interpretam os carbonatos da Guia como a subunidade 8 do topo do Grupo Cuiabá situada estratigraficamente abaixo das unidades, não-metamórficas, da Província Serrana.

As litologias carbonatadas desta unidade iniciaram sua deposição sobre diferentes tipos de diamictitos da unidade imediatamente inferior. Na porção pericratônica, a sedimentação foi quase que exclusivamente química (Formação Araras) enquanto nas partes distais, para leste e sudeste, aparecem os sedimentos pelíticos-químicos (Fácies Guia).

A Formação Araras é pouco conhecida no seu conteúdo fossilífero, mas no Grupo Corumbá, seu equivalente estratigráfico, foram identificados fósseis que têm sugerido uma idade vendiana para esta unidade (Fairchild 1978, Fairchild \& Sundaram 1981, Walde et al. 1982).

Unidade Superior (Grupo Alto Paraguai) Aflorando na Província Serrana, esta unidade se inicia por contato gradacional com o topo da unidade carbonatada para os arenitos da Formação Raizama. Uma espessura de $1.600 \mathrm{~m}$ foi descrita por Almeida (1964) para a Formação Raizama na Serra do Tombador. O topo do Grupo Alto Paraguai é composto de folhelhos, siltitos e arcósios finos da Formação Diamantino com espessuras que podem atingir mais de $3.000 \mathrm{~m}$ (Hennies 1966).

Os folhelhos Sepotuba, que têm atualmente sido considerados apenas uma fácies da Formação Diamantino (Barros et al. 1982), apresentam dados geocronológicos que indicam uma idade cambriana para a sua diagênese, com valores de $547 \mathrm{Ma}$ de acordo com a isócrona $\mathrm{Rb} / \mathrm{Sr}$ apresentada por Cordani et al. (1978).

AMBIENTE DEPOSICIONAL O ambiente no extremo sudeste do Cráton Amazônico, durante o Proterozóico Superior, caracterizava-se por apresentar uma borda cratônica fortemente influenciada pela glaciação ao lado de uma bacia marinha relativamente profunda, com aporte e sedimentação vindo do continente através de leques submarinos alongados de noroeste para sudeste formando depósitos do tipo fluxos gravitacionais subdivididos nas fácies proximais, intermediárias e distais (Figs. 4 e 5).

A fácies proximal pode ser individualizada em três associaçōes principais. As duas primeiras (Figs. 4-A e 4-B) são caracterizadas pela abundância de diamictitos associados e raros níveis de conglomerados e aos níveis areno-argilosos. $\mathrm{Na}$ associação B, os diamictitos estão intercalados com camadas de arenito conglomerático representando condições favoráveis
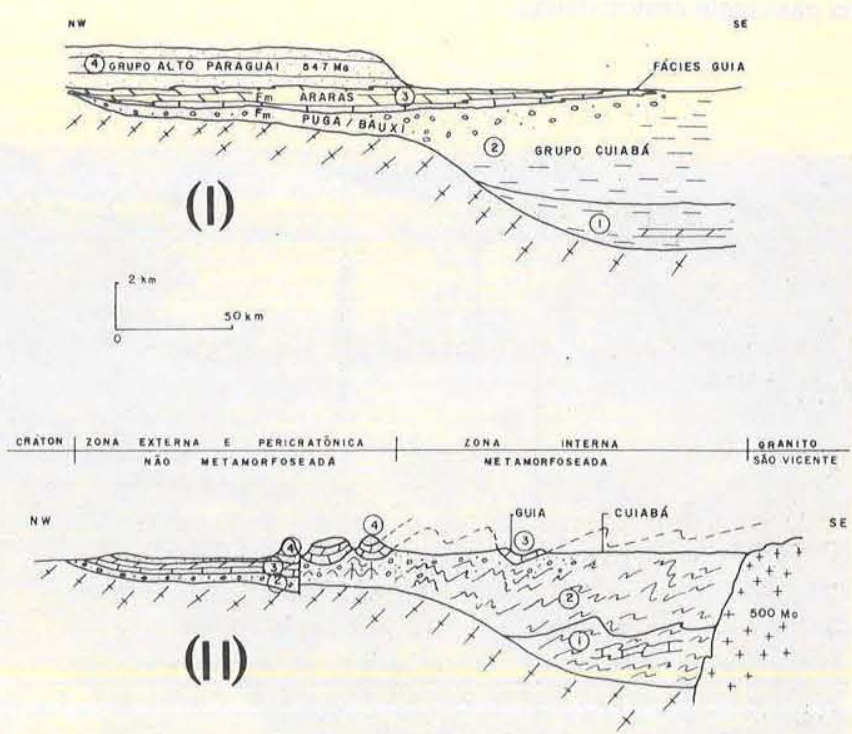

Figura 5 - Esquema evolutivo: I. sedimentação e II. deformação do cinturão Paraguai. 1. Unidade inferior; 2. unidade média turbidítica glaciogenética; 3. unidade média carbonata$d a ; 4$. unidade superior 
para uma sedimentação subaquática do tipo debris flow. A interpretaçāo da associação A é mais delicada, pois pode ser originada de um debris flow ou de uma sedimentação gláciomarinha. Finalmente, a associação $\mathbf{C}$, onde dominam os conglomerados por vezes gradacionais, associados a raros níveis de quartzitos e siltitos, foram interpretados por Alvarenga (1985) como depósitos de canais e intercanais de leques turbidíticos submarinos. As fácies intermediárias ou medianas (Fig. 4-D) caracterizam-se pela abundância de microconglomerados e arenitos grossos gradacionais que representam as partes medianas dos corpos em leques, originados de correntes turbidíticas menos densas que as da fácies proximais. As fácies distais (Fig. 4-E) são formadas por ritmitos com ocasionais intervalos $\mathrm{Tb}$ e $\mathrm{Tc}$ de Bouma e representam uma transição entre os leques submarinos médios e a sedimentação marinha de leque inferior.

Os diamictitos das fácies proximais alcançam bancos maciços de mais de $15 \mathrm{~m}$ de espessura com numerosos seixos, blocos e matacôes isolados que chegam a atingir $50 \mathrm{~cm}$ de diâmetro. Os turbiditos aí associados são geralmente grossos, com numerosas intercalações conglomeráticas, onde a base dos ciclos se apresentam um pouco erosivas (Alvarenga 1985). Nos raros turbiditos finos da fácies proximal alguns seixos isolados podem parecer entre os estratos laminados. Neste caso, os seixos isolados nāo estâo condicionados a depósitos por correntes gravitacionais mas à influência da contribuição glacial.

Os materiais glaciais continentais que estiveram acumulados na borda do Cráton Amazônico foram remobilizados e redepositados sob a forma de diamictitos, originados provavelmente de um debris flow subaquoso gerando e transicionando para turbiditos grossos e finos. Esses processos sâo bem descritos por Hampton (1972).

A sedimentação turbidítica, no Cinturão Paraguai, tem a contribuição de materiais transportados por grandes massas de gelos flutuantes. Estes materiais podem facilmente ser identificados pelos seixos isolados encontrados nas partes superiores, laminadas, dos ciclos turbidíticos (Foto 2), mas têm sua identificação mascarada nas fácies mais grossas.

Assim, grande parte dos diamictitos da Formação Puga não são tilitos continentais nem um simples depósito glácio-manho, mas provavelmente depósitos marinhos plataformais de frentes de geleiras remobilizadas por correntes gravitacionais na passagem cráton-bacia.
CONCLUSÕES As unidades não-metamórficas das formaçöes Bauxi e Puga passam lateralmente para as unidades superiores do Grupo Cuiabá, não havendo nenhuma evidência da presença de discordância entre essas unidades.

Os diamictitos e turbiditos grossos das formaçōes Bauxi, Puga e a parte média-superior do Grupo Cuiabá representam fácies gláciomarinhas retrabalhadas por correntes gravitacionais na borda do Cráton Amazônico. Processos semelhantes sāo discutidos por Schermerhorn (1974) e Marmo \& Ojakangas (1984).

A freqüente presença de diamictitos com significativa influência glacial, localizados estratigraficamente abaixo da Unidade Média Carbonatada (Fig. 3), sugere uma rápida mudança climática, na época, que culminou com o fim do período glacial.

Agradecimentos $\mathrm{O}$ autor agradece aos Professores Roland Trompette e Marcel Auguste Dardenne, pelo estímulo, sugestōes, críticas e valiosas discussões indispensáveis na realização deste trabalho; ao Departamento de Geologia e à SubReitoria de Pesquisa da UFMT, pelo apoio na realização das missões de campo; e ao CNPq, pela assistência financeira (Proc. 40.7171/83). O autor agradece, também, aos três revisores anônimos da Revista Brasileira de Geociências, pelas sugestōes apresentadas.

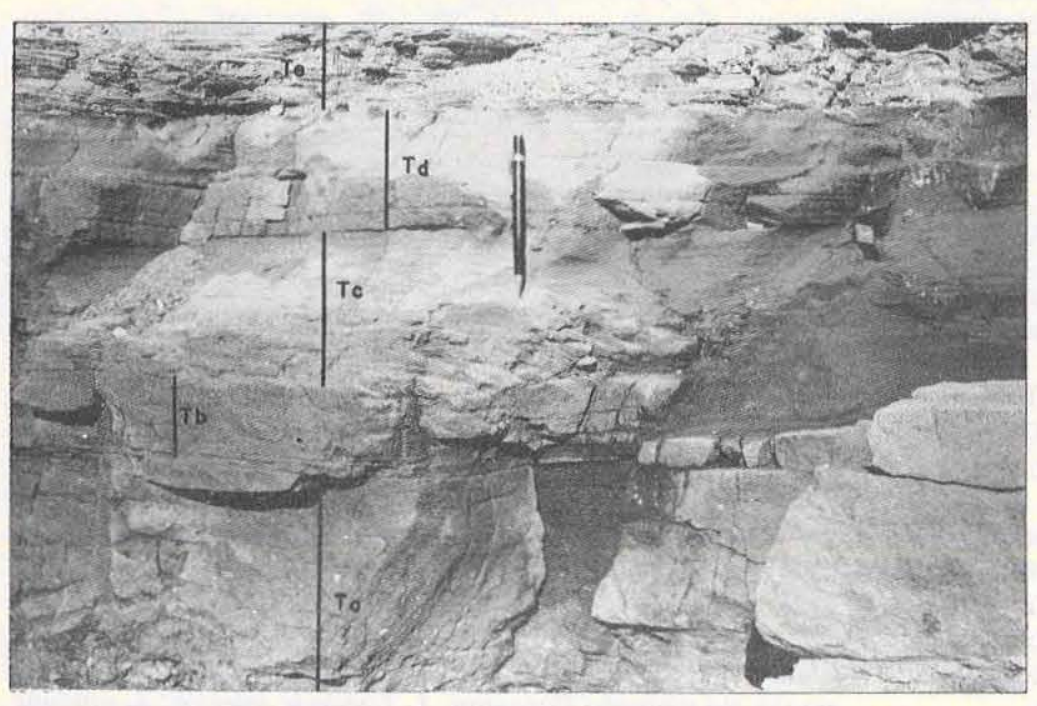

Foto 1: Seqüência de Bouma, mostrando suas subdivisões, situada na coluna C da figura 4

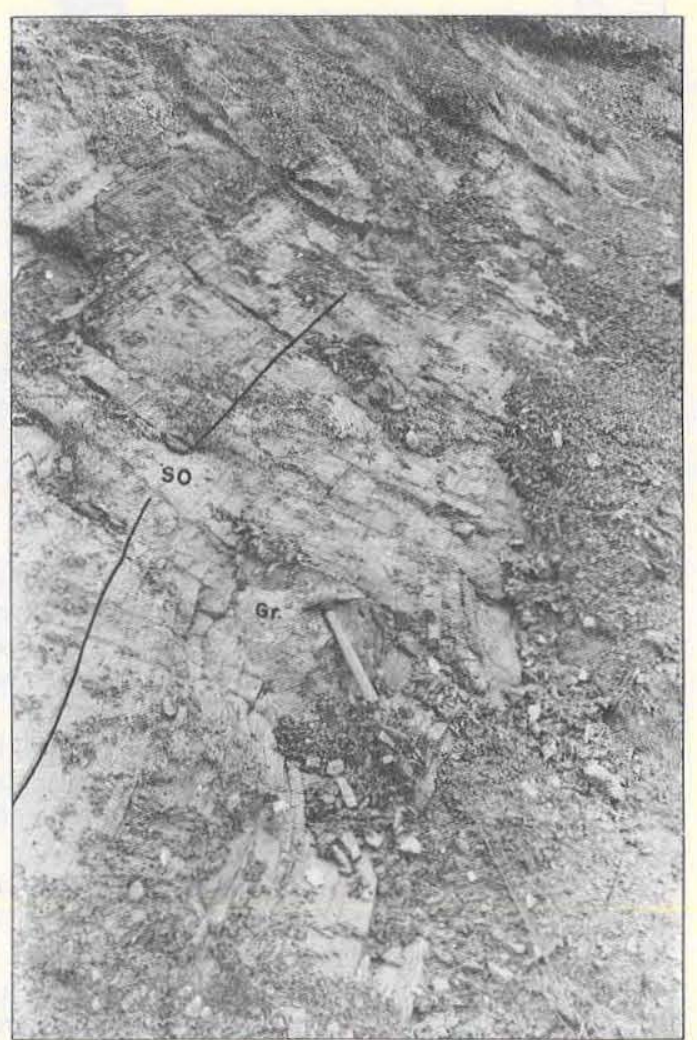

Foto 2: Filitos do Grupo Cuiabá com laminação (So) preservada, mostrando um mataçâo, isolado, de granito ( $\mathrm{gr}$ ) 


\section{REFERÊNCIAS BIBLIOGRÁFICAS}

ALMEIDA, F.F.M. de 1964. Geologia do centro-oeste matogrossense. Rio de Janeiro, DGM/DNPM, 137p. (Boletim 215).

ALMEIDA, F.F.M de. 1974. Sistema tectónico marginal do Cráton do Guaporé. In: CONGR. BRAS. GEOL., 28, Porto Alegre, 1974. Anais... Porto Alegre, SBG. v. 4, p. 11-17.

ALMEIDA, F.F.M. de. 1984. Província Tocantins - Setor Sudoeste. In: ALMEIDA, F.F.M. de \& HASUI, Y. coords. Pré-Cambriano do Brasil. São Paulo, Edgard Blücher, p. 265-281.

ALMEIDA, F.F.M. de. 1985. Alguns problemas das relaçöes geológicas entre o cráton amazónico e as faixas de dobramentos marginais a leste. In: SIMP. GEOL. DO CENTRO-OESTE, 2 , Goiânia, 1985. Ata... Goiânia, NCO/SBG. p. 3-14.

ALVARENGA, C.J.S. de. 1984. Dobramentos da Faixa Paraguai na borda sudeste do cráton amazônico. In: CONGR. BRAS. GEOL., 33, Rio de Janeiro, 1984. Anais... Rio de Janeiro, SBG. v. 7 p. 3258-3271.

ALVARENGA, C.J.S, de. 1985. Evidências de fácies turbidíticas grosseiras no Grupo Cuiabá, MT. In: SIMP, GEOL. DO CENTRO-OESTE, 2, Goiânia, 1985. Ata... Goiânia, NCO/SBG. p. 256-266.

ALVARENGA, C.J.S. de. 1986. Evoluçäo das deformaçōes polifásicas brasilianas na Faixa Paraguai, na região de Cuiabá, MT. In: CONGR. BRAS. GEOL., 34, Goiânia, 1986. Anais... Goiânia, SBG. v. 3, p. $1170-1175$.

BARROS, A.M.; SILVA, R.H. da; CARDOSO, O.R.F.A.; FREIRE, F.A.; SOUZA Jr., J.J. de; RIVETTI, M.; LUZ, D.S. da; PALMEIRA, R.C.B.; TASSINARI, C.C.G. 1982. Geologia. In: RADAMBRASIL. Folha SD. 21 Cuiaba. geologia, geomorfologia, pedologia, vegetação e uso potencial da terra. $\mathrm{MME} / \mathrm{SG}$. (Lev. Rec. Nat. 25).

CORDANI, U.G.; KAWASHITA, K.; THOMAS F\%., A. 1978. Applicability of the rubidium-strotium methods to shales and related rocks. In: COHEE, B.V. et al. eds. Contributions to the geologic time scale. Am. Ass. Petrol. Geol, Studies in Geol., 6:93-117.

FAIRCHILD, T.R. 1978. Evidências paleontologicas de uma possivel idade ediacariana ou cambriana inferior para parte do Gnupo Corumbá, Mato Grosso do Sul. In: CONGR. BRÁS. GEOL., 30, Recife, 1978. Bol. Esp... Recife, SBG. 1, p. 181.

FAIRCHILD, T.R. \& SUNDARAM, D. 1981. Novas evidencias palinológicas sobre o Grupo Corumba, Ladário, Mato Grosso do
Sul. In: SIMP. GEOL. DO CENTRO-OESTE, 1, Goiânia, 1981. Bol. Resumos... Goiânia, SBG/NCO. p. 13.

FIGUEIREDO, A.J. de A. \& OLIVATTI, O. 1974. Projeto Alto Guaporé. Goiânia. DNPM, v, 11, 173 p. (Relatório final integrado)

HAMPTON, M.A. 1972. The role of suabqueous debris flow in generating turbidity currents. J. Sed. Petrology, 42(4):775-793.

HENNIES, W.T. 1966. Geologia do centro-norte mato-grossense. São Paulo, 65p. (Tese de Mestrado, Esc. Polit. Univ. São Paulo).

LUZ, J.S. \& ABREU FILHO, W. 1978. Aspectos geologicos econômicos da Formaçäo Araras do Grupo Alto Paraguai, MT̃. In: CONGR. BRAS GEOL., 30, Recife, 1978. Anais... Recife, SBG. v.4, p. 1816-1826

LUZ, J.S.; OLIVEIRA, A.M; LEMOS, D.B.; ARGOLO, J.L.; SOUZA, J.O. de; TANNO, L.C.; SOUZA, N.B.; ABREU FILJHO, W. 1978. Projeto Província Serrana. Goiânia. DNPM/CPRM,v. 1, 105p. (Relatório final)

LUZ, J.S; OLIVEIRA, A.M.; SOUZA, J.O; MOTTA, J.F.M.; TANNO, L.C.; CARMO; L.S. do; SOUZA, N.B. de. 1980. Projeto Coxipó. Goiânia. DNPM/CPRM, v. 1, 136 p. (Relatório final)

MARMO J.S, \& OJAKANGAS, R.W. 1984, Lower proterozoic glaciogenic deposits, eastern Finland. Geol. Soc. Amer. Bull., 95(9): $1055-1062$

RIBEIRO FIL.HO, W.; LUZ, J.S.; ABREU FILHO, W. 1975. Projeto Serra Azul. Goiânia. DNPM/CPRM. v. 1, 104 p. (Relatório fínal).

SCHERMERHORN, L.J.G. 1974. Late Precambrian mixtites: glacial and/or non glacial? Amer. J.Sci., 274:673-824.

SCHOBBENHAUS, C.; CAMPOS, D.A.; DERZE, G.R.; ASMUS, H.B. coord. 1981. Mapa geológico do Brasil e da area oceánica adjacente incluindo depósitos minerais. Escala 1:2.500.000. Brasília, DNPM. 4 fls.

WALDE, D.H.G.; LEONARDOS, O.H.; HAHN, G; PFLUG, H.D. 1982. The first precambrian megafossils from South America, Corumbella Werneri. An. Acad. bras. Cienc., 54(2):461.

MANUSCRITO 408 Recebido em 04 de dezembro de 1986 Revisão aceita em 11 de março de 1988

Na maioria das escolas, o ensino de ciências não trabalha com a identificação, o reconhecimento e a compreensão do mundo físico e do mundo dos seres vivos, não faz relação entre o dia-a-dia da criança e a ciência que se estuda. 